Ann. Biol. anim., Bioch., Biophys., I995, 5 (3), 361-381.

\title{
ÉTUDE DES VARIATIONS DES TENEURS EN GLUCIDES CYTOPLASMIQUES ET MEMBRANAIRES DU DACTYLE AU COURS DE L'ANNÉE
}

\author{
B. GAUSSERES \\ avec la collaboration technique de Valérie Goujon-Frasç̧ors \\ et B. Teilhard de Chardin (1) \\ Laboratoire des Métabolismes \\ Centre national de Recherches zootechniques, Jouy-en-Josas (Seine-et-Oise)
}

\section{SOMMAIRE}

Un Dactyle $S 26$ a été semé et exploité normalement en 1957. En 1958 des échantillons ont été prélevés à chaque coupe pour étudier l'évolution de la composition des plantes au cours des cycles successifs et l'influence du stade d'interruption de chaque cycle sur la composition des repousses. Après séparation des plantes en limbes, gaines, tiges, nous avons dosé dans chacune de ces fractions les glucides solubles (sucres réducteurs, polysaccharides à chaînes courtes, fructosanes) et les glucides membranaires (hémicelluloses, cellulose, lignine).

\section{INTRODUCTION}

Les glucides constituent une fraction importante de la plante (de l'ordre de 60 p. I0o). La méthode de Weende les sépare en deux fractions dont l'une, dite cellulose brute, comprend la majorité de la cellulose, un résidu d'hémicelluloses, de matières azotées et de lignine, et l'autre, dite extractif non azoté, comprend à côté de substances diverses, des glucides cytoplasmiques et plus de la moitié des constituants de la membrane (la plus grande partie des hémicelluloses et une fraction variable de la lignine). L'utilisation digestive et les valeurs nutritives des éléments de ces deux fractions sont très différentes. Il est donc intéressant de les doser séparément. En outre, les variations en glucides de réserve comme celles des composants de la membrane peuvent donner une idée de l'évolution physiologique des plantes soumises à des exploitations de types différents. Pour ces raisons nous avons séparé les glucides cytoplasmiques et membranaires d'un Dactyle $S 26$ en étudiant les cycles successifs et l'influence du stade d'interruption de chaque cycle sur la composition des repousses.

(1) Amélioration des Plantes. Domaines Expérimentaux du Pin. Le Pin-au-Haras (Orne). 
Nous avons dosé séparément les sucres réducteurs (glucose-fructose), les polysaccharides à chaînes courtes (saccharose), les fructosanes, les hémicelluloses, la cellulose et la lignine.

Répartition et désignation des prélèvements de Dactyle

(Nombre de jours de croissance)

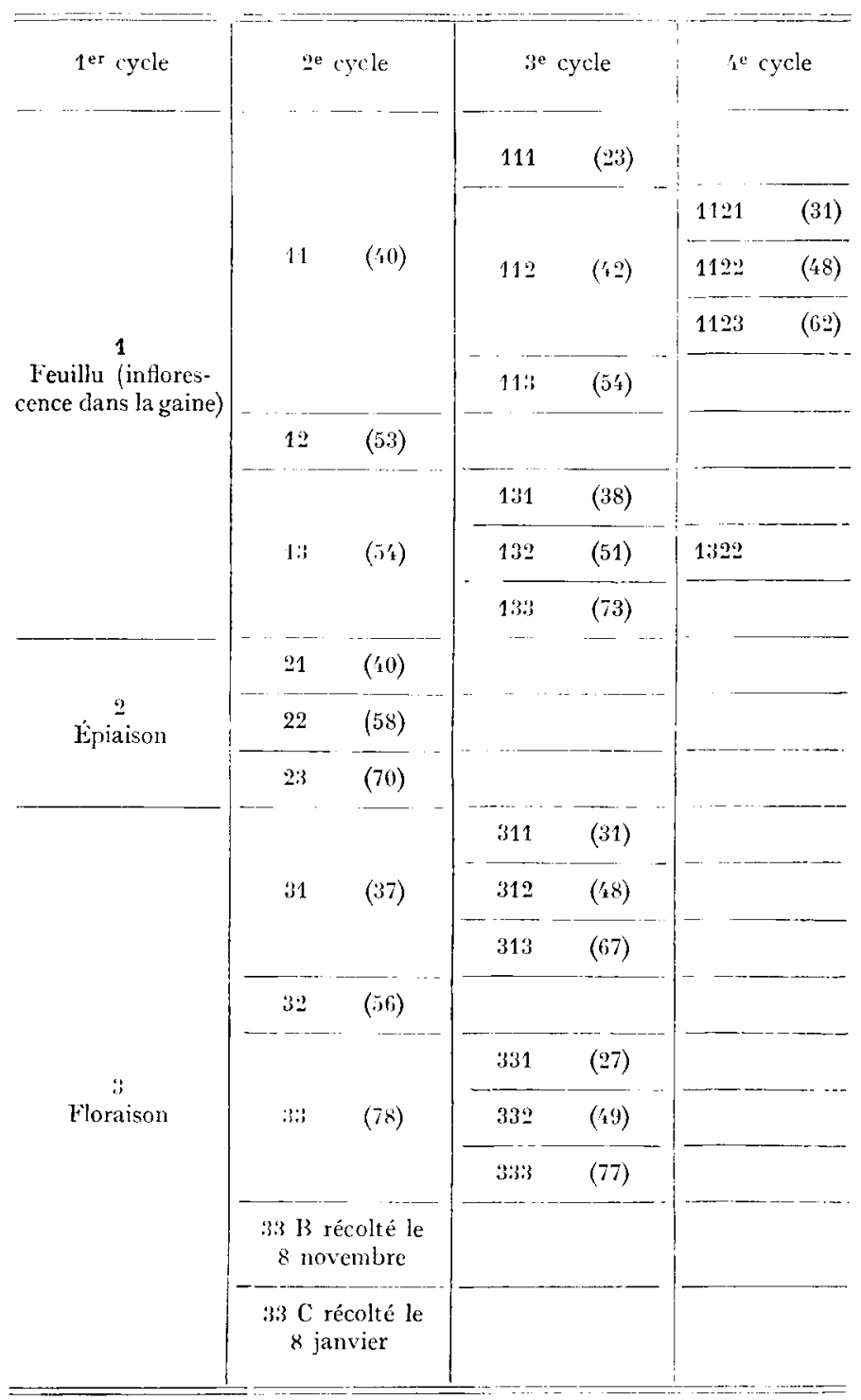

Les teneurs en matières azotées ont déjà fait l'objet d'une publication (Guḱguen et Fauconneau, r960). Nous ne les donnons qu'à titre indicatif dans le tableau I. 


\section{MATÉRIEL EXPÉRIMENTAL}

L'expérience porte sur un Dactyle $S: C$, semé au printemps 1957 sur une parcelle du C. N. R. Z. (sol argilo-humifère), fumé par un apport phospho-potassique complété par 80 unités d'azote (ammonitrate) au premier cycle et 60 unités aux cycles suivants. La récolte est faite en 1958 (après une exploitation normale en 1957), à trois stades de développement pour chaque cycle récolté.

Le schéma ci-contre indique la répartition des différentes coupes et les durées de croissance correspondantes en jours. La nomenclature des coupes (également utilisée dans les graphiques et tableaux) permet de connaître : le numéro d'ordre du cycle de végétation (nombre total de chiffres), le stade de développement (chiffres des unités) et la, ou les coupes antérieures (chiffres précédant le chiffre des unités). Les trois stades de coupe choisis correspondent : pour le premier cycle, au stade feuillu (échantillon I), à l'épiaison (échantillon 2) et à la floraison (échantillon 3); pour les cycles suivants, à des durées de végétation de 4 semaines (échantillons 2 I et I3I par exemple), 6 semaines (échantillons 22 et I 32 par exemple) et 8 semaines (échantillons 23 et I33 par exemple).

\section{Mode de prélèvement et traitement des échantillons}

Un échantillon représentatif pesant environ $3 \mathrm{~kg}$ est prélevé sur la totalité de la parcelle fauchée (Io $\mathrm{m}^{2}$ au minimum). La production par $\mathrm{m}^{2}$ est calculée en poids de matière fraîche et de matière sèche. Les limbes, gaines, tiges, fleurs et éventuellement débris et plantes adventices, sont séparés avec soin et pesés aussitôt après la fauche. On détermine leurs proportions relatives après passage au four à circulation d'air $\left(70^{\circ} \mathrm{C}\right)$, pendant is heures. La durée movenne entre la fauche et la mise au four est de 3 à 4 heures.

\section{MÉTHODES D'ANALYSE}

Le schéma suivant résume les opérations effectuées pour extraire et doser les différents constituants. L'azote est dosé par la méthode de Kjeldhal.

Dactyle (poudre séchée)

Éthanol $80^{\circ}$ (à la température ambiante pendant $18 \mathrm{~h}$ )

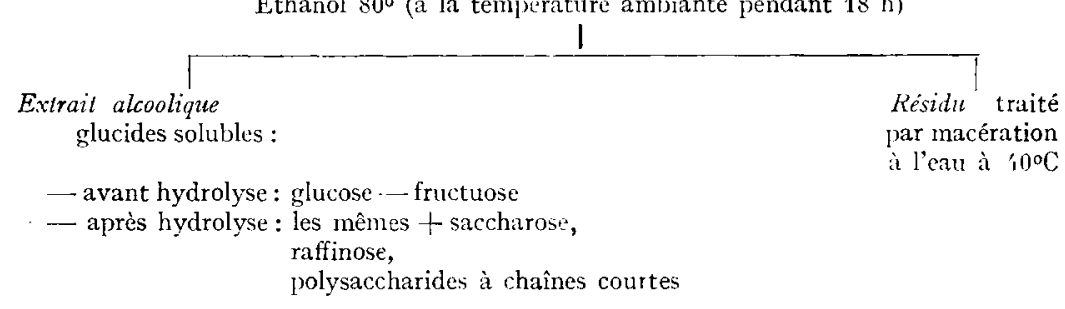

$\begin{array}{ll}\text { Exirait aqueux: fructosanes } & \text { Résidu hydrolysé par } \\ & \mathrm{SO}_{4} \mathrm{H}_{2} \text { à } 5 \%(\mathrm{P} / \mathrm{p}) \text { (à } \\ \text { l'ébullition } 3 \text { heures) }\end{array}$

$\begin{array}{ll}\text { Hydrolysat } z \%: & \text { Résidu } 5 \% \text { traité par } \\ \text { Hemicellulose }=\text { pouvoir réducteur } \times 0,9 & 5 \mathrm{O}_{4} \mathrm{H}_{2} \dot{\mathrm{a}} 7 \mathrm{2} \%(\mathrm{P} / \mathrm{p})(4 \mathrm{~h} \text { à } \\ \text { (xylanes }+ \text { hexosanes) } & \text { la température ambiante) } \\ \text { puis par } \mathrm{SO}_{4} \mathrm{H}_{2} \grave{a} 3 \% & 3 \% \\ & (3 \text { heures à l'ébullition). }\end{array}$

Ilydrolysal 72 \% :

Cellulose $=$ pouvoir réducteur $\times 0,9$

(cellulose vraie + xylanes résiduelles)

Résidu séché et calciné

Schéma du fractionnement utilisé pour l'analyse des glucides 


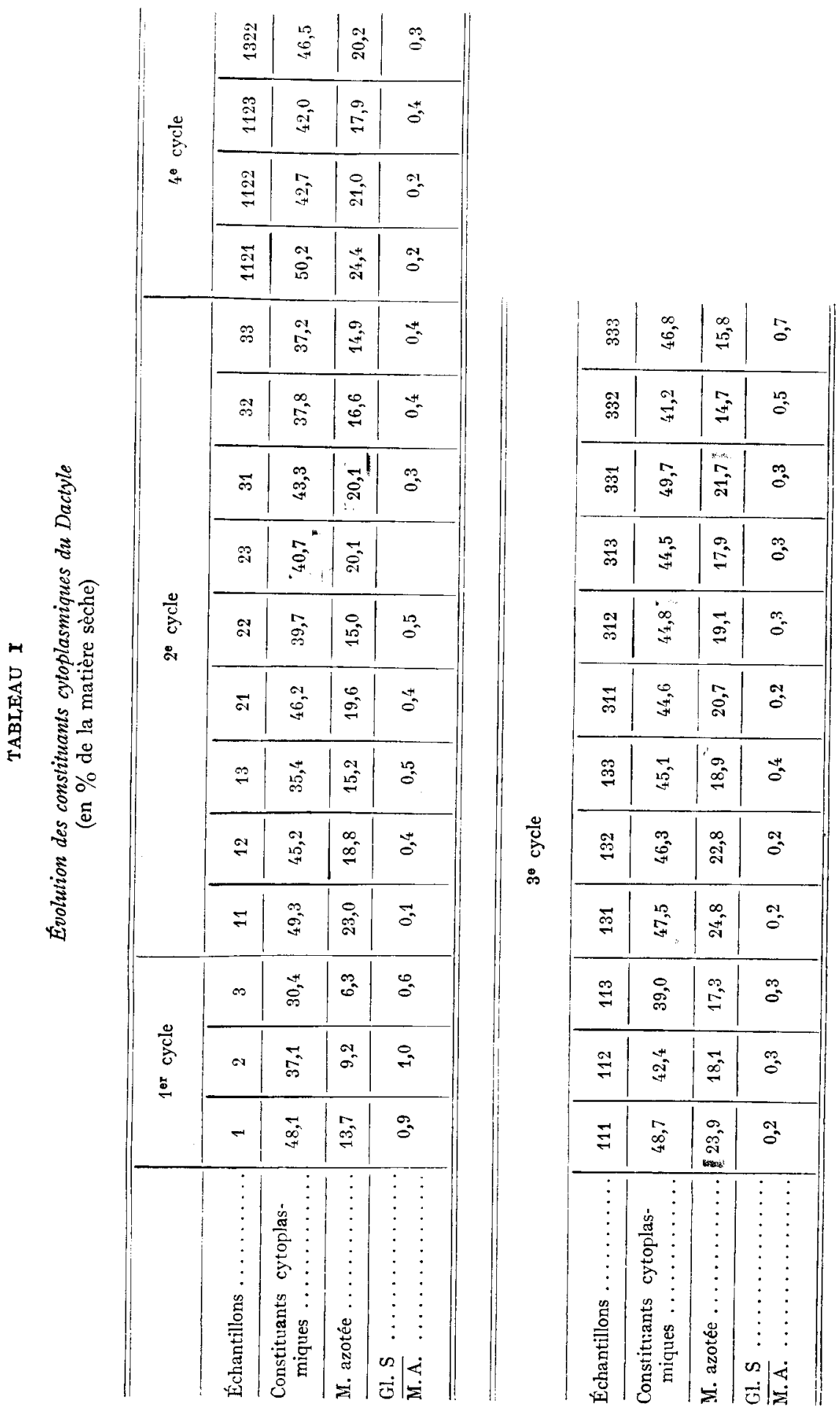


Les pouvoirs réducteurs (sucres réducteurs, sucres totaux après hydrolyse, hydrolysats des constituants membranaires) sont mesurés par la méthode iodométrique de Somogyı (I952) qui donne un équivalent glucose ; les fructosanes par la méthode au Résorcinol chlorhydrique (RARY, 1945) qui donne un équivalent fructose. Les constituants membranaires sont fractionnés par la méthode de JARRIGE (I96r), mais nous avons fait précéder l'extraction aqueuse d'une extraction alcoolique. Nous en discuterons plus loin l'importance. La lignine, évaluée en retranchant le poids des cendres du résidu final obtenu après la série des extractions précédentes, est en réalité la fraction organique de ce résidu.

\section{RÉSULTATS}

Croissance pondérale des différents organes au cours des différents cycles

$$
\text { (graphique I) }
$$

Étant donné la taille des parcelles, les rendements n'ont qu'une valeur comparative. Il est cependant intéressant de suivre l'évolution des différents organes. Au premier cycle, à partir de l'épiaison, les limbes ne se développent plus. C'est la
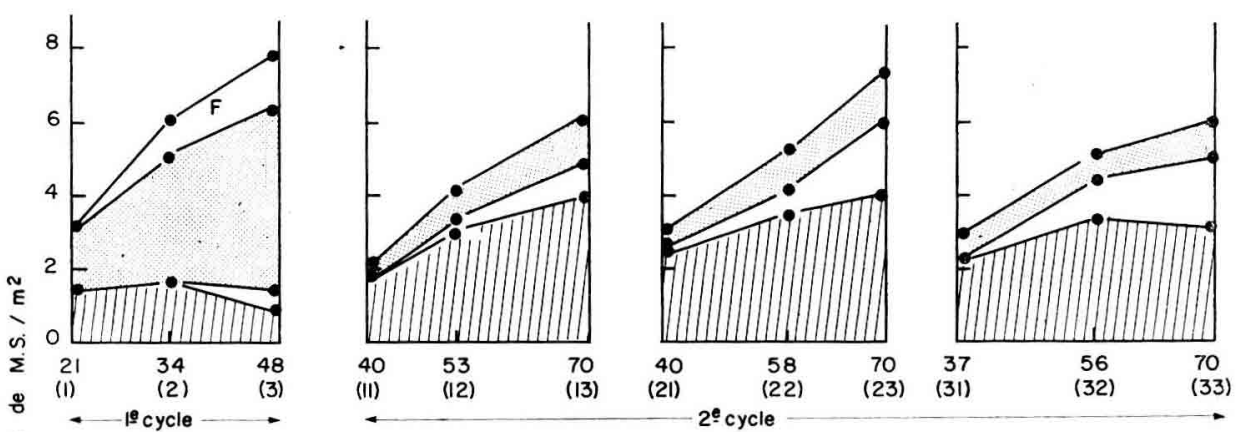

응
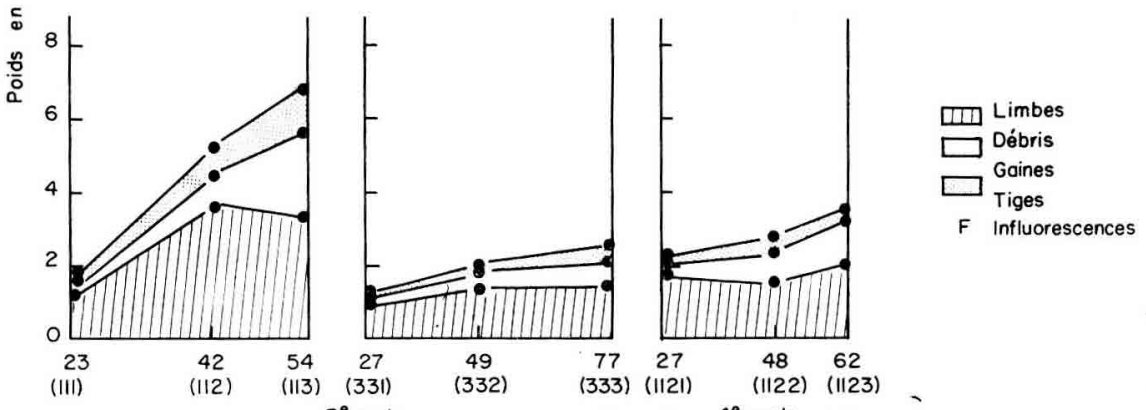

(III)

(II2) (II3) $\quad 3$ (331)

(332)

(333) (II2I)

(1122) (1123)

GRAPHQQUe I. - Croissance pondérale des différents organes du Dactyle au cours des différents cycles

période où les tiges et gaines croissent très rapidement pour constituer environ les $2 / 3$ de la plante à la floraison. Ce que nous appelons " débris " comprend des plantes adventices et des limbes rouillés. Ils constituent un pourcentage d'autant plus important que la coupe est plus tardive, surtout à cause de la présence des limbes 


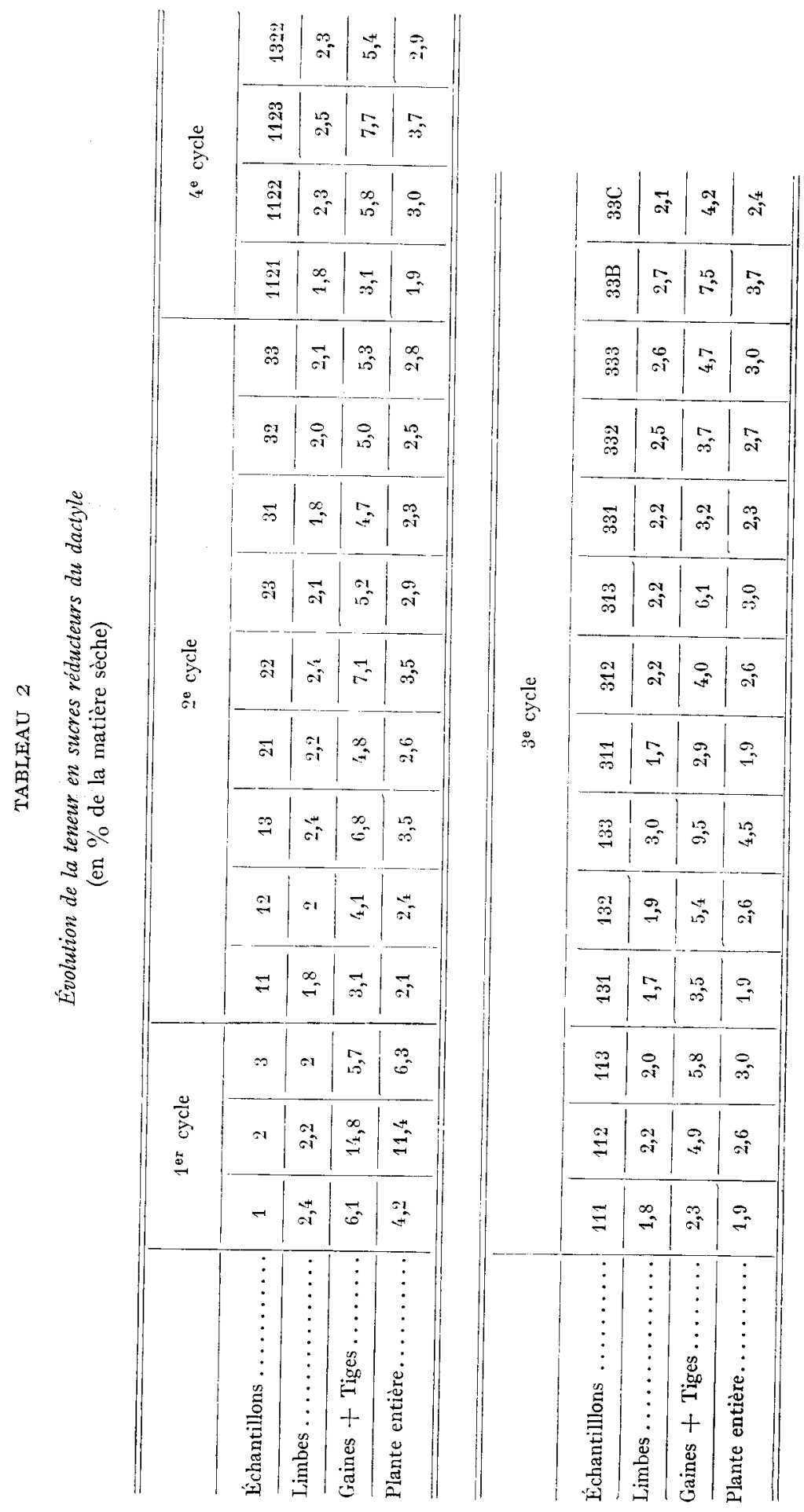


rouillés. Le deuxième cycle (II-I2-I3) issu d'un premier cycle interrompu au stade feuillu est particulier, car au moment de la fauche au stade $r$, l'inflorescence se trouve dans la gaine à une hauteur variable mais généralement inférieure à celle de la coupe ce qui ne permet pas le développement des bourgeons axillaires. On obtient ainsi des plantes dont le développement physiologique est le même que celles du premier cycle ; la proportion de limbes est plus faible. Dans les autres cas, les ébauches d'inflorescence sont sectionnées, de nouveaux axes feuillus se développent et les plantes contiennent peu ou pas de tiges. Les limbes atteignent d'autant plus tôt leur poids maximum que la saison est plus avancée $\left(5^{8}\right.$ jours au mois de juin contre 42 jours au mois de septembre). La courbe de croissance est en réalité peu précise puisqu'il n'y a que trois prélèvements pour chaque cycle. Les gaines constituent un pourcentage de la plante à peu près constant et faible ( I3 à 20 p. roo).

Lorsque les conditions climatiques sont favorables à la rouille, (cas de l'automne I958), les limbes âgés sont attaqués. Classés dans les " débris ", ils constituent un pourcentage de plus en plus important quand la plante vieillit. Un temps de croissance de $5^{\circ}$ jours paraît alors un optimum lorsque les conditions météorologiques ne sont pas favorables. Il ne semble pas opportun de trop prolonger la durée de développement des plantes, du moins pour la variété étudiée.

\section{Glucides solubles}

Les sucres réducteurs des limbes (tabl. 2, graph. 2) varient assez peu (entre I p. Ioo et $3 \mathrm{p}$. roo de la matière sèche). Au premier cycle ils diminuent régulièrement à partir du stade feuillu, tandis qu'aux cycles suivants ils augmentent jusqu'à six semaines de croissance. Après six semaines, malgré une tendance générale à l'augmentation, leurs variations ne sont pas toujours de même sens. I,es tiges et les gaines en renferment de I, 5 à 7 fois plus que les limbes et apparaissent comme des organes de conduction. Au premier cycle, lerrs teneurs en sucres réducteurs sont élevées à l'épiaison, puis diminuent jusqu'à la floraison. Aux cycles suivants elles augmentent lorsque le développement des plantes se poursuit. Dans la plante entière, au premier cycle, les sucres réducteurs atteignent II,4 p. Ioo au moment de l'épiaison. En deçà et en delà de ce stade il y en a beaucoup moins (respectivement 4,2 et 6,3 p. roo). Aux cycles suivants, dans presque tous les cas il y a une faible "augmentation" entre 4 semaines et 8 semaines de croissance.

La saison ne semble pas avoir d'effet déterminant, bien qu'au printemps les valeurs soient plus élevées.

Ces résultats confirment céux de JARRIGE (I954), qui a observé des teneurs maxima au printemps suvies d'une diminution, puis d'un plateau autour de valeurs de l'ordre de $r, 5$ à 2,5 p. roo et ceux de WAITE et Boyd (I953 $b$ ), qui trouvent, pour l'année I952 sur un Dactyle $S 143,0,3$ à 2,I p. Ioo de M.S., le maximum se situant également au printemps.

Les polysaccharides à chaînes courtes - saccharose (tabl. 3, graph. 2). - sont plus importants (excepté quelques cas particuliers) dans les limbes que dans les tiges et les gaines ( $\mathrm{I}, 3$ à 2 fois plus). L,es premiers en contiennent de 2,0 à $6,5 \mathrm{p}$. Ioo et les secondes de $\mathrm{I}, 4$ à $6 \mathrm{p}$. Ioo. Les teneurs sont très élevées dans les plantes récoltées en hiver ( $\mathrm{I}_{4}, 2 \mathrm{p}$. Ioo pour l'échantillon 33B). Au premier cycle, 
les pourcentages de polysaccharides à chaînes courtes des tiges + gaines et des limbes, varient dans le même sens. Ils diminuent entre le stade feuillu et la floraison. Il est probable que les valeurs trouvées aux stades feuillus correspondent à des maxima, conformément aux résultats de WAI'TE et Boyd (I953 a). Ce parallélisme se conserve aux cycles suivants, mais quand la plante vieillit les limbes s'appauvrissent beaucoup plus que les gaines qui gardent une composition sensiblement constante. I)ans la plante entière on a de $\mathrm{I}, 7 \mathrm{p}$. Ioo à $8 \mathrm{p}$. roo de polysaccharides

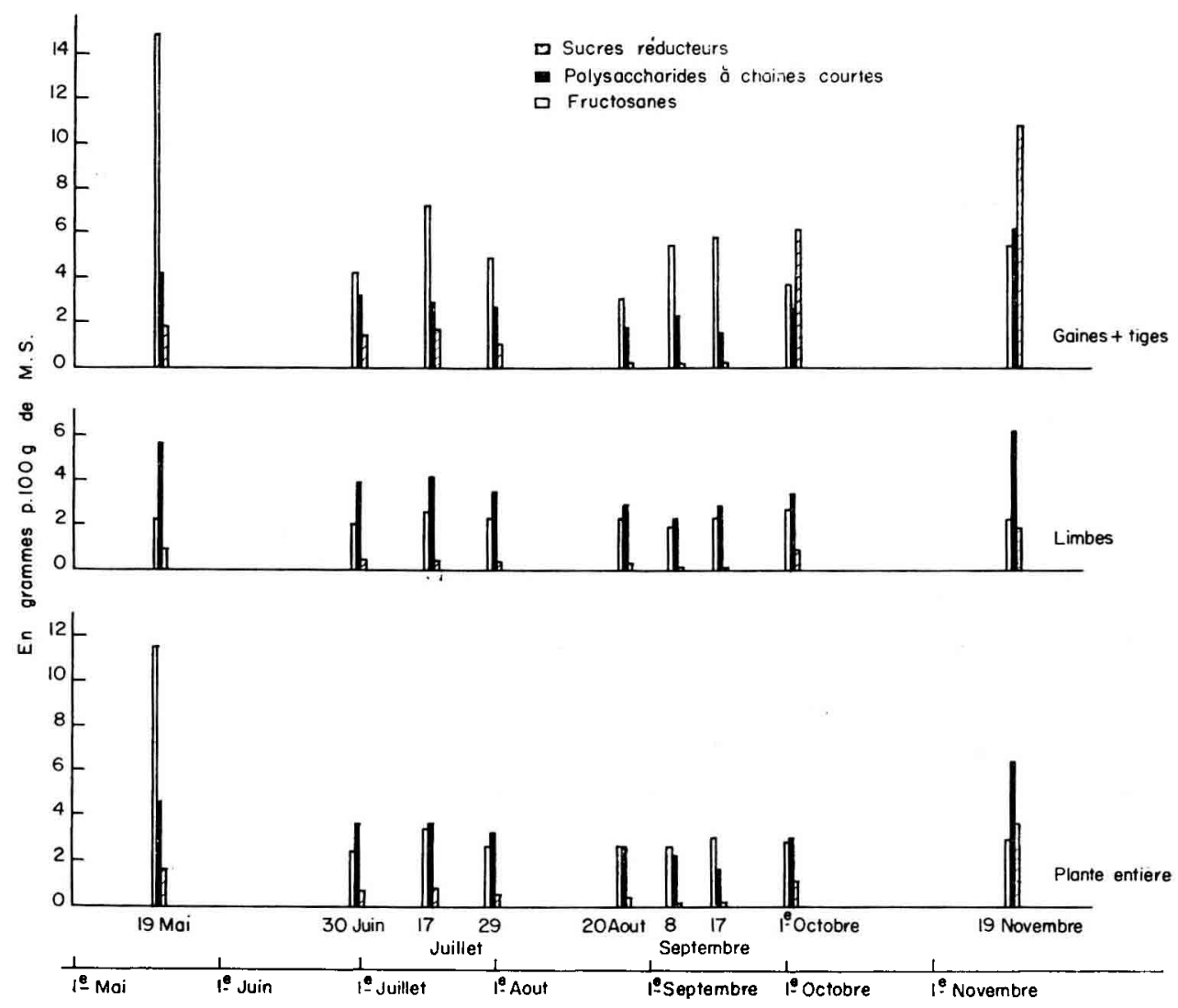

Grapinque 2. - Evolution, au cours de l'annéc, des glucides solubles des plantes entières de Dactyle

à chaînes courtes et il ne semble pas exister de variations systématiques avec l'âge. La saison par contre joue un rôle important. Du début de la croissance en mai, jusqu'à la fin du mois de juilllet, les valeurs diminuent passant de 5,5 p. IOO à I, 9 p. IOO puis durant aôit et septembre demeurent aux alentours de $2,5 \mathrm{p}$. Ioo pour augmenter considérablement à l'automne ( $44 \mathrm{p}$. Ioo pour les gaines de réserves sur pied (1) ; 8 p. IOO pour la plante entière). JARRIGE (I954) trouve également une diminution à partir du printemps, mais WAYTE et BOYD (I953 b) signalent une légère augmen-

(1) Plantes des échantillons $33^{\mathrm{B}}$ et $33^{\mathrm{C}}$ qui au lieu d'être récoltées au même moment que culles de l'échantillon 33 , l'ont été respectivement le 8 novembre et le 8 janvier. 
TENEURS EN GIUCIDES DU DACTYIE

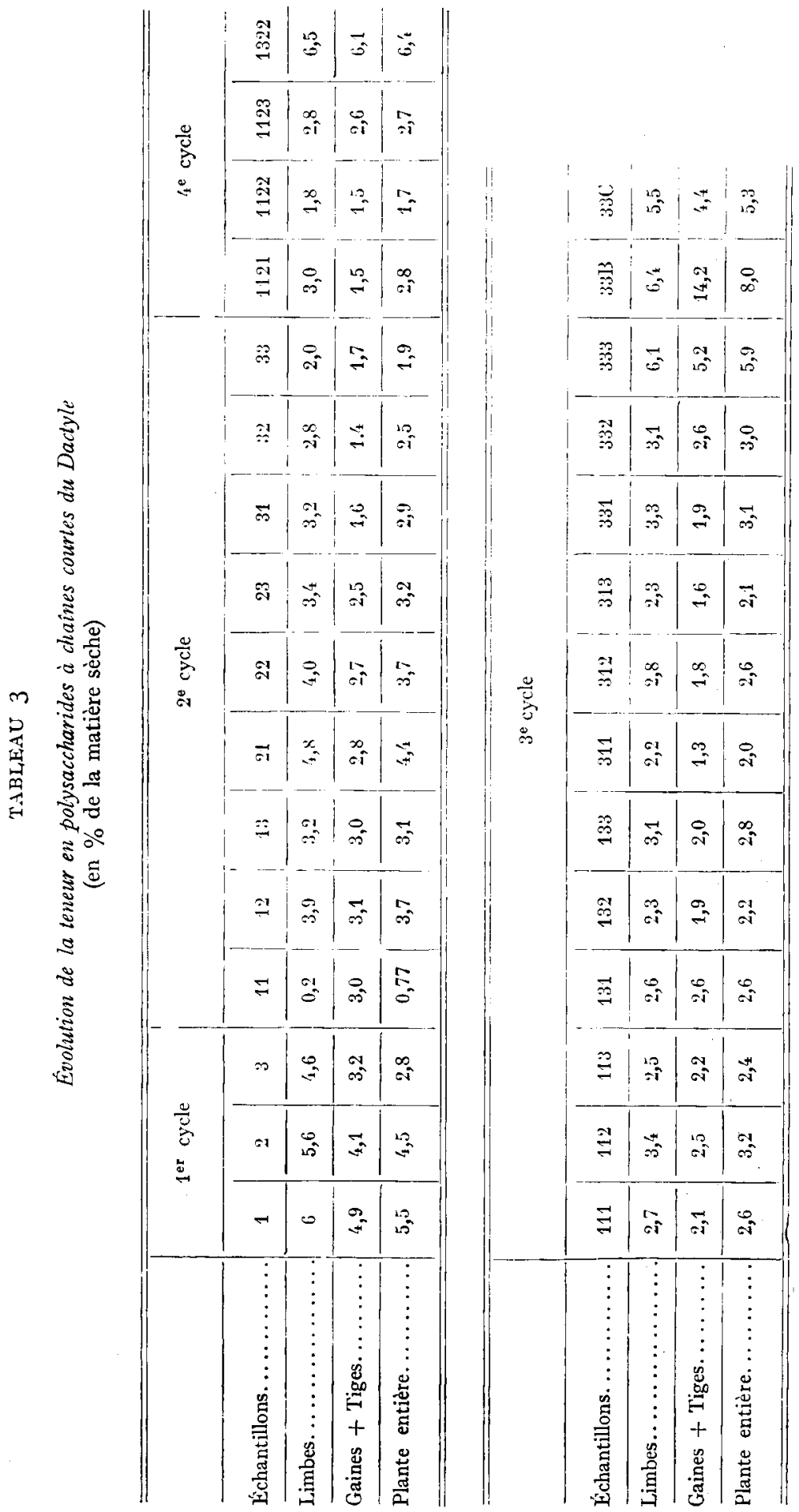


tation au mois de juillet (les valeurs passant de $x$ p. Ioo à 5 p. Ioo) qui pourrait être due à la sécheresse qui a ralenti la croissance des plantes.

Les Fructosanes, comme l'ont déjà remarqué certains auteurs, JARRIGE (I954), WAITE et Boyd (I953 $a$ et $b$ ), WAITE (I957-I958) sont peu importants dans le Dactyle. D'après nos résultats (tabl. 4,graph. 2), les limbes, en particulier, en sont dépourvus (o, I à 0,9 p. Ioo pour la plupart des échantillons). Les tiges et gaines en contiennent légèrement plus, entre 0,2 p. Ioo et $\mathbf{I}, 7$ p. I00, ce qui donne pour la plante entière, des valeurs moyennes comprises entre $0, \mathrm{I}$ p. Ioo et 0,6 p. xoo. Les plantes du premier cycle sont beaucoup plus riches, notamment au stade feuillu (2,8 p. IOo). I1 y a une diminution pendant l'épiaison et la floraison. Aux cycles suivants, on observe les mêmes variations, mais les valeurs trouvées sont beaucoup trop faibles pour être caractéristiques. On observe les maxima pour les échantillons récoltés après six semaines de croissance. I'influence de la saison est ici assez nette. On retrouve en automne les teneurs relativement élevées observées au printemps $(2,8 \mathrm{p}$. Ioo dans la plante entière et 8 , I p. Ioo dans les gaines pour l'échantillon $33 \mathrm{~B}$ ) après un plateau particulièrement bas en été $(0,6$ à $0,003 \mathrm{p}$. roo dans la plante entière).

Les glucides solubles totaux (tabl. 5) sont donc moins importants dans les limbes que dans les tiges et les gaines (2,6 p. IoO à II,5 p. Ioo contre 4,9 à I7,2 p. Ioo). L,es plantes récoltées en hiver en contiennent nettement plus, les teneurs de leurs limbes sont de II,2 p. Ioo contre I9,9 p. Ioo pour leurs tiges plus gaines (échantillon 33B). Au premier cycle, la plante s'appauvrit à partir du stade feuillu (maximum probable signalé plus haut). Aux cycles suivants, les variations sont beaucoup plus faibles, phénomène prévisible puisque le Dactyle deneure de "type feuillu ». Les conditions climatiques (influence de la saison) jouent certainement un rôle important. On observe deux maxima, l'un au printemps (I 2,4 p. Ioo à 8 p. IOO), l'autre en automne (I , 8 p. Ioo pour l'échantillon 333 et I5, I p. Ioo pour l'échantillon 33 B). Ce phénomène a déjà été observé par WAITE (I953), JARRIGE (I954), BAKER et GARWOOD (I96r).

\section{Constituants membranaires}

Pour les constituants membranaires, on peut exprimer les résultats : soit en pourcentage de la matière séche totale, soit en pourcentage de la membrane. L,e premier mode d'expression est le plus habituel puisque ce sont les taux de cellulose p. Ioo de la matière sèche (cellulose Weende) qui servent au calcul de la valeur nutritive des fourrages. Le deuxième mode d'expression est commode lorsque l'on veut comparer la composition d'échantillons dont les teneurs en membranes sont très différentes (JARRIGE I963).

Dans tous les cas, nous parlerons de lignine corrigée. Enn effet, la lignine brute, résultat des extractions successives, contient une certaine proportion de matières azotées résiduelles dépendant de la teneur en matière azotée des échantillons. JourNET et JARRIGE (I962) ont calculé pour le Dactyle une droite de régression

$$
\mathrm{Y}=\mathrm{I}, 39 \mathrm{X}+3, \mathrm{I} 5
$$

dans laquelle $\mathrm{Y}$ représente la teneur en matières azotées $\mathrm{p}$. Ioo de lignine brute et $\mathrm{X}$ la teneur en matières azotées totales du fourrage. A l'aide de cette équation, 


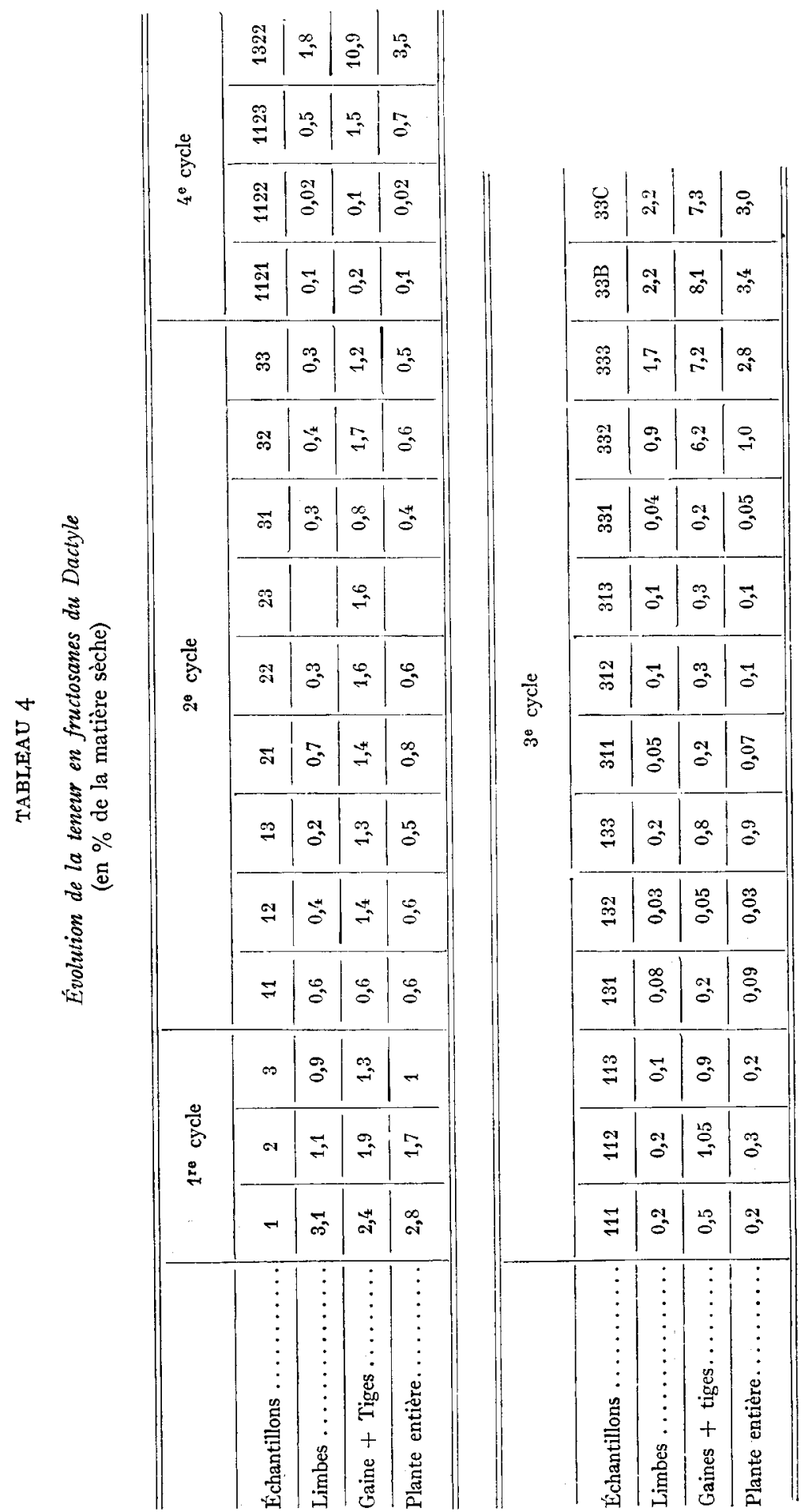




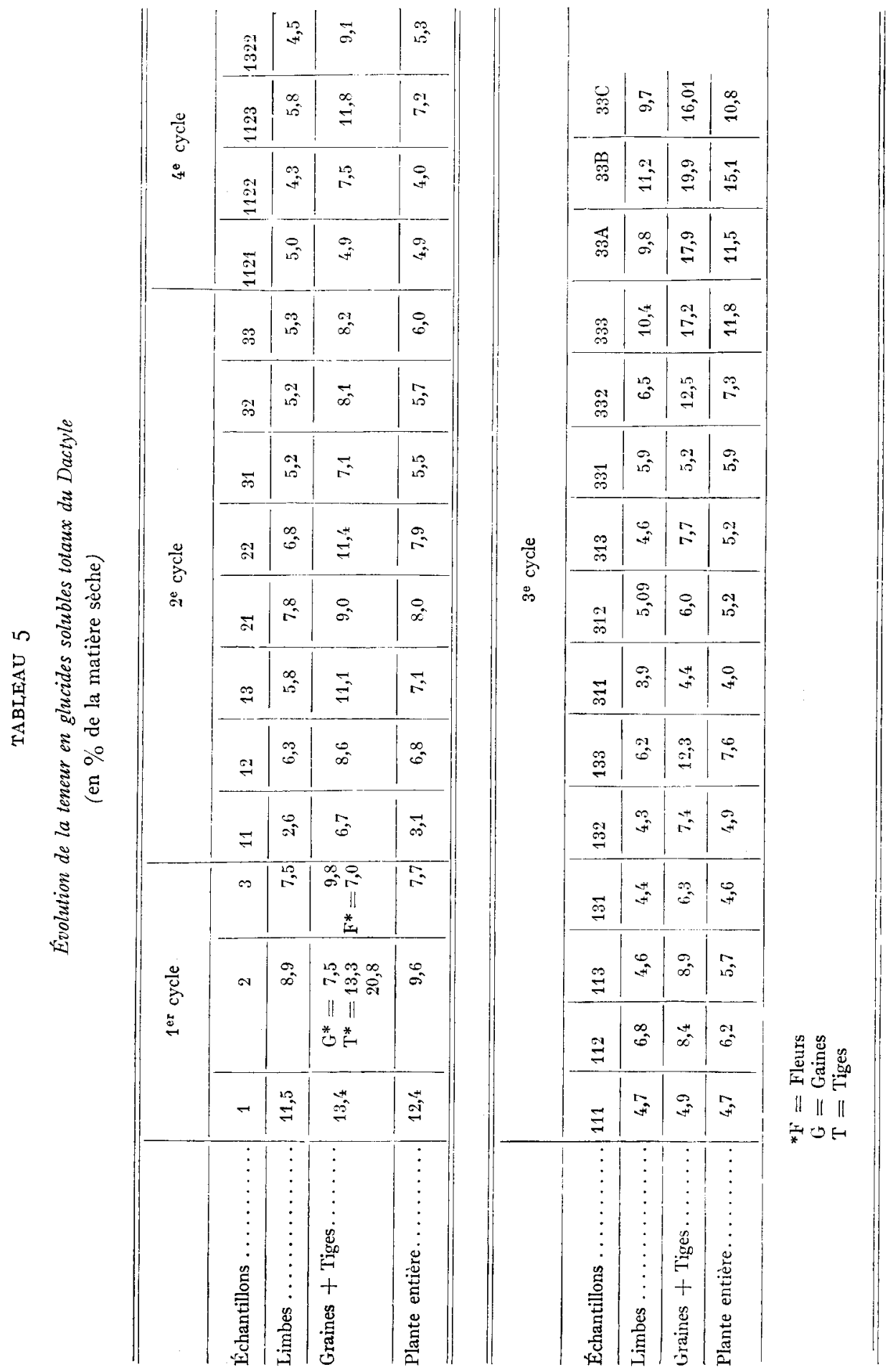


nous avons corrigé systématiquement toutes les valeurs " lignine brute ", résultats des extractions successives. Cette droite de régression a en réalité été établie pour des plantes entières de Dactyle. Nous l'avons cependant appliquée à des cas extrêmes : des limbes d'une part, des tiges et gaines d'autre part.

Résultats exprimés cu pourcentage de la matière sèche (tabl. 6 et 7).

Dans les limbes, au premier cycle, on passe de $39 \mathrm{p}$. Ioo de membranes au stade feuillu à $45 \mathrm{p}$. Ioo à la floraison. I1 y a donc une évolution très rapide des plantes.

\section{TABIEAU 6}

Éro'ution de la teneur on membrane ct composants membranaires des limbes du Dactyle (en \% de la matière sèche)

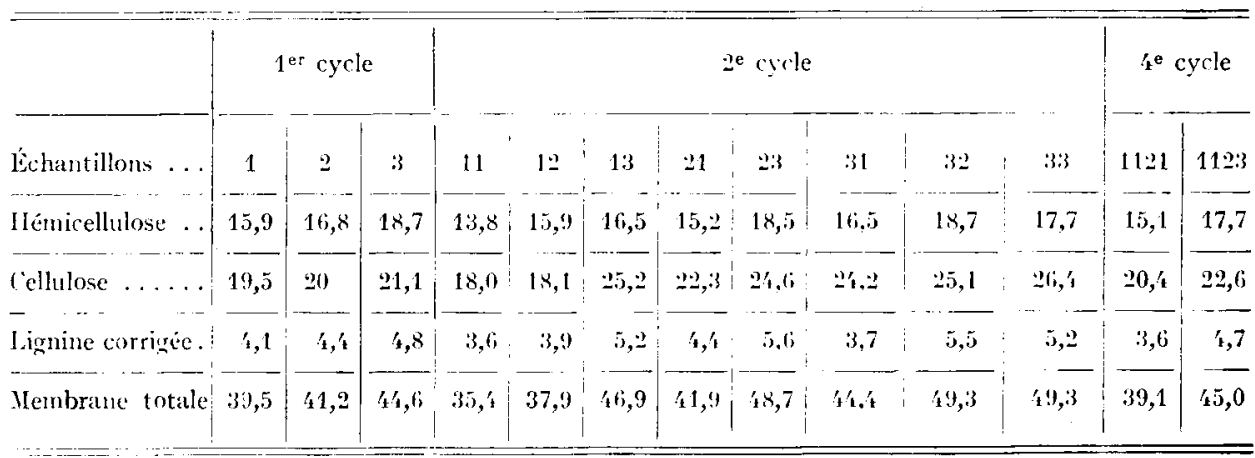

$\because \because$ cycle

\begin{tabular}{|c|c|c|c|c|c|c|c|c|c|}
\hline Echantillons & 111 & 112 & $11: 3$ & 312 & $::: 1$ & $3: 32$ & $33: 3$ & $83 \mathrm{~A}$ & $23: 313$ \\
\hline IIénicellılose . . & $1 i, j$ & 16,3 & $18,{ }^{\prime}$ & 17,3 & $13,: 1$ & 17,3 & 15,7 & $16 i, 7$ & 15,7 \\
\hline Celluloie .... & $2 \mathrm{~L}, \mathrm{i}$ & בְ, & $=-26,8$ & 23,8 & 201.7 & $\overline{\because 1,6 i}$ & $\because 2.1$ & 21,7 & $\overline{20,5}$ \\
\hline $\begin{array}{lllll}\cdots- & -\cdots & -- & \cdots\end{array}$ & -- & --- & - & -- & - & & $\cdots$ & - & - \\
\hline I.ignine corrigie. & 3,9 & i, & 5,9 & 5,5 & 3,9 & 5,1 & 4,6 & 1,1 & $\therefore, 0$ \\
\hline Membrane totale & 39,8 & is, 1 & 51,1 & $\{1, i\}$ & די, & 17,0 & 42,4 & 12.5 & $\{10,2$ \\
\hline
\end{tabular}

Aux cycles suivants, on ne constate pas toujours le même phénomène : certann: cycles (le $2^{\mathrm{e}}$ cycle II-I2-I3 et le $3^{\mathrm{e}}$ cycle II I-I I 2 -I I 3 gagnent de l'ordre de II points entre 4 et 8 semaines de croissance; en revanche au $3^{\text {e }}$ cycle 33 I-332-333, le taux de membranes est moins important en fin qu'en début de cycle. Si l'on excepte le $\mathrm{I}^{\mathrm{er}}$ cycle $(\mathrm{I}-2-3)$ et le $2^{\mathrm{e}}$ cycle (I I-I2-I3), il n'y a pas de différences significatives entre les différents cycles. Il n'y a pas de variations dans la proportion de membranes avec la saison. Seul l'âge des plantes semble déterminant. Quand les membranes deviennent plus importantes, les composants membranaires : hémicelluloses, cellulose, lignine, varient tous dans le même sens et gagnent approximativement le même 
nombre de points ( 2 à 5 pour les hémicelluloses et la cellulose, I à 2 pour la lignine). L'incrustation par la lignine est donc proportionnellement plus importante (jusqu'à 70 p. Ioo d'augmentation entre 4 et 8 semaines de croissance), sauf au premier cycle où elle ne passe que de $4, \mathrm{I}$ p. Ioo à 4,8 p. Ioo (soit I 6 p. Ioo d'augmentation). Pour l'ensemble des échantillons de limbes on a en moyenne i6 p. Ioo d'hémicelluloses, $22 \mathrm{p}$. Ioo de cellulose et $5 \mathrm{p}$. Ioo de lignine.

\section{TABIEAU 7}

Evolution de la teneur en membrane et en composants membranaires des gaines (et des tiges ${ }^{* *}$ ) du Dactyle

(en \% de la matière sèche)

\begin{tabular}{|c|c|c|c|c|c|c|c|c|c|c|c|}
\hline \multirow[b]{2}{*}{ Échantillons } & \multicolumn{3}{|c|}{$1^{\mathrm{er}}$ cycle } & \multicolumn{6}{|c|}{$2^{\mathrm{e}}$ cycle } & \multicolumn{2}{|c|}{$4^{\mathrm{e}}$ cycle } \\
\hline & $1^{* *}$ & 2 & $3^{* *}$ & $11^{* *}$ & 12 & 13 & 22 & 31 & 32 & 1121 & 1123 \\
\hline Ilémicellulose & 22,8 & $\mathrm{G}^{*}=2 \mathbf{4}, \mathbf{k}$ & $21,{ }^{\prime}$ & 21,9 & 21,6 & 21,1 & 21,4 & 22,5 & 23,7 & 21,5 & 20,3 \\
\hline Cellulose . & 23,0 & $\begin{array}{l}\mathrm{G}^{*}=29,2 \\
\mathrm{~T}^{*}=31,0\end{array}$ & 33,7 & 28,8 & 25,8 & 24,5 & 25,8 & 26,0 & 26,5 & 25,4 & $2 t, 6$ \\
\hline Lignine corrigée & 3,0 & $\begin{array}{l}\mathrm{G}^{*}=6,2 \\
\mathrm{G}^{*}=5,3\end{array}$ & 8,1 & 6,2 & 3,9 & 4,6 & 3,5 & 4,6 & 5,2 & 4,2 & 4,5 \\
\hline Membrane totale & 48,8 & $\begin{array}{l}\mathrm{G}^{*}=59,8 \\
\mathrm{~T}^{*}=56,7\end{array}$ & 63,2 & 56,9 & 51,3 & 50,2 & 50,7 & 53,1 & 55,4 & 51,1 & $49,4_{4}$ \\
\hline
\end{tabular}

\begin{tabular}{|c|c|c|c|c|c|c|c|c|c|}
\hline \multirow[b]{2}{*}{ Échantillons } & \multicolumn{8}{|c|}{$3^{e}$ cycle } & \multirow{6}{*}{$\begin{array}{c}* \mathrm{G}=\text { gaines } \\
\mathrm{T}=\text { tiges } \\
* * \text { gaines }+ \text { tiges }\end{array}$} \\
\hline & 111 & 113 & 133 & 312 & 331 & 332 & 333 & $33 \mathrm{~B}$ & \\
\hline Hémicellulose & 22,2 & 20,3 & 18,7 & 19,7 & 21,4 & 22,6 & 19,6 & 16,9 & \\
\hline Cellulose & 24,8 & 26,3 & 24,2 & 24,7 & 26,4 & 26,2 & 24,4 & 20,3 & \\
\hline Lignine corrigée. & 3,7 & 4,0 & 4,4 & 4,4 & 4,5 & 4,7 & 3,8 & 3,2 & \\
\hline Membrane totale & 50,7 & 50,6 & 47,3 & 48,8 & 52,3 & 53,5 & 47,8 & 40,4 & \\
\hline
\end{tabular}

Dans les tiges et les gaines, si au premier cycle, les membranes s'épaississent beaucoup quand la plante vieillit, on passe de 49 p. roo à 63 p. Ioo, aux cycles suivants on ne retrouve rien de semblable et la fraction gaines + tiges (essentiellement composée de gaines) garde un pourcentage de membranes assez constant et voisin de 50 . Les tiges et les gaines contiennent toujours plus de membranes que les limbes. La différence peut être de I5 à 20 points quand les plantes sont jeunes, mais n'est plus que de quelques points après 8 semaines de croissance. Dans les cycles autres que le premier, alors que les limbes s'enrichissent en membranes quand la plante 
vieillit, les tiges et gaines gardent une composition plus corstante. La saison ne semble pas avoir d'influence.

Les proportions respectives des différents constituants membranaires exprimées en p. Ioo de la M.S. ne sont pas les mêmes dans les gaines et tiges et dans les limbes. Dans les gaines et tiges, au premier cycle, il y a plus d'hémicelluloses, de cellulose et de lignine. Ceci est en partie dû au développement global important des membranes. En fin de croissance, la cellulose et la lignine augmentent et les hémicelluloses demeurent stationnaires, tandis que pour les limbes, les hémicelluloses augmentent également. Sur les échantillons des autres cycles on note surtout une teneur plus élevée d'hémicelluloses, de l'ordre de 20 p. roo dans les tiges et gaines, contre I 5 p. Ioo en moyenne pour les limbes. Les taux de cellulose et de lignine sont légèrement différents, mais sans que cela soit significatif. On a en moyenne, pour l'ensemble des tiges et gaines, excepté celles du premier cycle, 2 I p. Ioo d'hémicelluloses, 25 p.Ioo de cellulose et $4 \mathrm{p}$. Ioo de lignine, ce qui correspond à $5 \mathbf{I}$ p. roo de membrane totale.

Pour la plante entière (tabl. 8), l'augmentation des constituants membranaires

\section{TABIEAU 8}

Erolution de la teneur en membranes des plantes entières du Dactyle (en \% de la matière sèche)

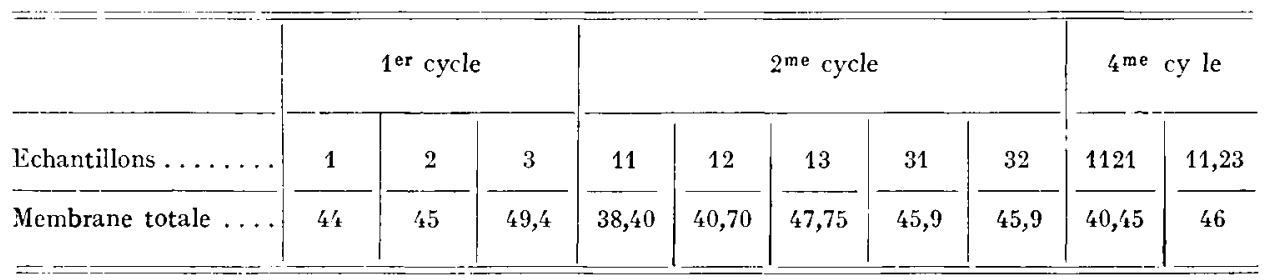

\begin{tabular}{l|c|c|c|c|c|c|c|c}
\hline & \\
\hline Echantillons ....... & 111 & 113 & 312 & 331 & 332 & 333 & $33 \mathrm{~B}$ \\
\hline Membrane totale .... & 41,25 & 51 & 47,1 & 40 & 47,95 & 41,25 & 40,45 \\
\hline
\end{tabular}

est constante et régulière lorsque la plante vieillit. Cette évolution, nette au premier cycle, est encore plus rapide dans le deuxième cycle (II-I2-I3). Le pourcentage moyen de membranes des différents cycles est assez constant. Comme nous l'avons déjà signalé, la saison n'agit guère sur l'évolution des plantes, du moins dans le cas particulier étudié. Pour l'ensemble des échantillons analysés entièrement, la teneur moyenne en membrane des plantes est de 44 p. Ioo.

Résultats exprimés en pourcentage de la membrane (graph. 3).

Les hémicelluloses représentent $3^{6}$ à $4 \mathrm{I}$ p. Ioo de la membrane des limbes (moyenne 38 p. IOo) et 33 à 47 p. Ioo de celle des tiges et des gaines (moyenne 4I p. IOO). Il y a peu de variations sauf dans les tiges et gaines du premier 
cycle où elles constituent une proportion importante de la membrane qui diminue lorsque la plante vieillit (diminution passive due à l'augmentation des autres constituants).

La cellulose entre pour 47 à 54 p. Ioo (moyenne 5I p. Ioo) dans la membrane (les limbes et pour 47 à 53 p. Ioo (moyenne 50 p. IOo) dans celle des gaines et des tiges. Comme précédemment, pour les limbes, on ne constate aucune variation significative. Seules les tiges et gaines s'enrichissent en cellulose au premier cycle lorsque la plante vieillit atteignant des valeurs maxima de $55 \mathrm{p}$. Ioo que l'on ne retrouve plus dans les autres échantillons.

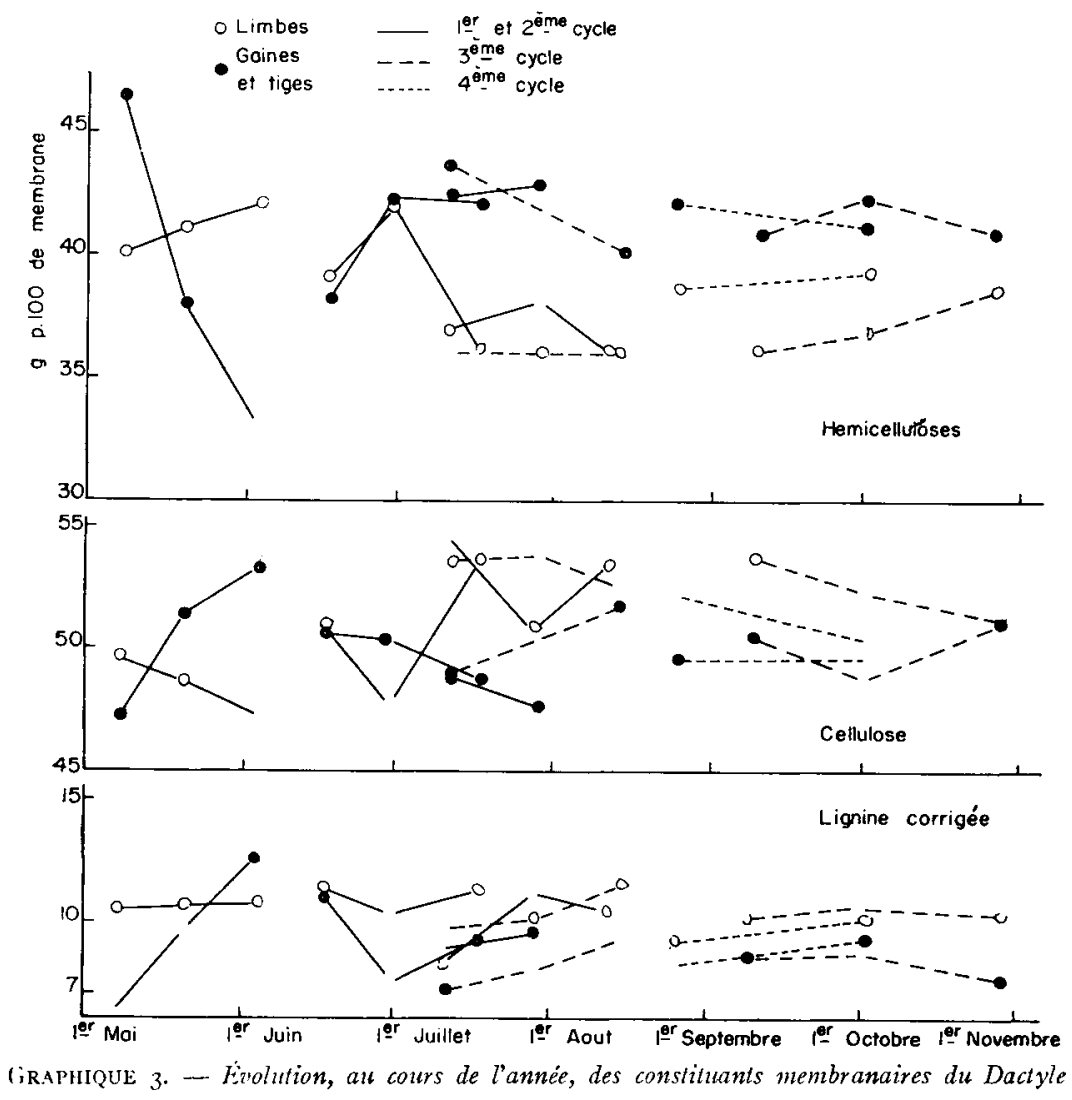

Pour la lignine on est conduit aux mêmes remarques, les valeurs extrêmes étant 8 et $\mathrm{r} 2 \mathrm{p}$ Ioo pour les limbes, et 6 et $\mathrm{I} 3 \mathrm{p}$. Ioo pour les tiges et gaines. Les valeurs moyennes sont, respectivement, Io et 9 p. Ioo. Seules les gaines et tiges du premier cycle montrent une évolution puisque entre le stade feuillu et la floraison le taux de lignine double, passant de 6 p. Ioo à I3 p. Ioo.

Il semble donc que les membranes de Dactyle conservent une composition très constante. C'est ce que note JARRIGE (I963) après analyse de I5 plants de Dactyle. D'une façon générale les membranes des limbes sont cependant plus riches en cellulose et lignine et moins riches en hémicelluloses que celles des tiges et des gaines. 


\section{DISCUSSION}

La période juin-août de l'année $195^{8}$ est caractérisée par une croissance extrêmement importante des plantes, due à une pluviométrie régulièrement répartie.

$\begin{array}{cc}\text { Précipitations mensuelles en } \mathrm{mm} \\ \text { Mai } & 53,5 \\ \text { Juin } & \mathrm{I} 09,3 \\ \text { Juillet } & \mathrm{I} 2,8 \\ \text { Aô̂t } & 48,7 \\ \text { Septembre } & 43, \mathrm{I} \\ \text { Octobre } & 45 \\ \text { Novembre } & 43,5\end{array}$

Répartition des pluies en 1958

Il est indispensable également de tenir compte, parallèlement à cette pluviométrie favorable, de l'abondance de la fumure déjà signalée.

La photosynthèse produit des hexoses qui peuvent être polymérisés très rapidement, jusqu'à constituer des fructosanes éléments de réserve, s'ils ne sont pas utilisés pour assurer les besoins de croissance de la plante. Par conséquent, si la photosynthèse est inférieure aux besoins de la croissance, les réserves ne se constituent pas et celles qui existent sont utilisées. Le taux de fructosanes est donc le reflet d'un équilibre, entre la photosynthèse et la croissance, qui dépend des facteurs climatiques et de la fumure. Comme les conditions de développement étaient favorables pendant l'été I958, le Dactyle analysé n'était pas à même de constituer des réserves. De plus, en fauchant, on laisse une partie des réserves dans les chaumes. Chez le Dactyle, les fructosanes sont stockés dans le premier entre-nœud (PHILLIPS et al. I954). Les faibles teneurs que 1'on trouve dans les limbes montrent bien qu'ils sont inaptes au stockage important des glucides de réserve. Pour séparer quantitativement les différents éléments des plantes (limbes, tiges, etc.), il est indispensable d'opérer sur des plantes fraîches. Or, durant le temps de la séparation, 3-4 heures à la température ambiante, il se produit des transformations à l'intérieur de la plante. LAIDLAW (I952) trouve qu'au bout de deux heures de conservation à la température ambiante, les hexoses n'ont pas varié, alors que le saccharose a diminué de 6,2 p. Ioo à 5, I p. Ioo et les fructosanes de 9,6 p. Ioo à 9,2 p. Ioo. Au bout de 24 heures de séchage, les hexoses ont augmenté de 3 à 4,8 p. Ioo aux dépens des fructosanes (9,2 p. Ioo à 5,2 p. I0o), cependant que le saccharose ne varie plus. En conséquence, par suite du traitement auquel les échantillons ont été soumis, il se peut que les quantités dosées de fructosanes soient légèrement inférieures à celles qui existaient dans le fourrage frais.

Pour de nombreux échantillons, il semble qu'il y ait parallèlement à l'augmentation des taux de saccharose, une diminution de ceux d'hexoses et de fructosanes. L'accumulation du saccharose peut provenir, soit d'une polymérisation des hexoses, 
soit d'une migration à partir des réserves des racines et du collet, sans doute pour assurer une pression osmotique élevée du suc cellulaire pendant les périodes froides.

Il est manifeste que la portion de la plante laissée dans le sol présente une grande importance quant à la régulation des glucides dans la partie végétative fauchée ou consommée par les animaux. BAKER et GARwood (I96I) ont étudié la composition en glucides solubles des racines et chaumes du Dactyle. Ils ont remarqué que les chaumes contiennent de 2 p. Ioo à I 8 p. Ioo de glucides solubles, les maxima correspondant aux périodes de faible croissance ( $8 \mathrm{p}$. Ioo en automne). Au cours de l'hiver, ces teneurs diminuent régulièrement. Les fructosanes constituent la presque totalité de ces réserves et sont stockés en quantités d'autant plus importantes que le rythme des coupes est moins rapide. Par contre, dans les racines, les quantités de glucides solubles (essentiellement des fructosanes) sont beaucoup plus faibles, de l'ordre de 2 p. Ioo, avec un maximum de 4 p. Ioo au début de l'hiver. ERkKi HuoKUNA (I960) trouve dans des racines de Dactyle des valeurs légèrement plus élevées d'environ 6 p. IOO. HYDER et SNEVA (I952) constatent également une accumulation dans les racines lorsque la croissance diminue. Il semble donc que les réserves glucidiques de la partie végétative située au-dessus de la barre de coupe (dans les conditions de fauche habituelles) reflètent sensiblement la constitution de celles des racines et des chaumes qui vont permettre à la plante un nouveau développement plus ou moins rapide. On doit laisser à chaque coupe, en particulier à l'entrée de l'hiver, un " potentiel végétatif " suffisant.

Si 1'on calcule pour chaque échantillon la valeur du rapport glucides solubles totaux/matières azotées (tabl. I) on trouve des valeurs de l'ordre de 0,20 à 0,30 , excepté pour le premier cycle. Dans les plantes du premier cycle et celles des cycles tardifs (échantillons I33, 33r, 333 et II23), ces valeurs sont supérieures et atteignent I,05. FAUCONNEAU et JARRIGE (I955) avaient trouvé sur Dactyle I 5 danois demi-tardif, des rapports de $I, 43$ à 2,47 au premier cycle et d'environ 0,60 sur des repousses. Le développement important et constant des plantes est sans doute responsable de ces différences. Dans le cas de l'utilisation d'un tel Dactyle pour l'ensilage, la pénurie de glucides devrait être prise en considération.

Pour pouvoir fractionner les glucides cytoplasmiques, nous avons dî effectuer une extraction alcoolique. JARRIGE (I96I) a étudié l'influence de l'extraction alcoolique sur le fractionnement ultérieur des composants membranaires. Il constate une action limitée mais sensible qui aboutit généralement à une détermination par défaut de la cellulose. On doit donc tenir compte de ce fait dans l'interprétation des résultats.

Les hémicelluloses telles que nous les déterminons contiennent les hémicelluloses vraies et des substances pectiques. Cependant, les substances pectiques ne constituent rarement plus de $2 \mathrm{p}$. Ioo de la matière sèche des graminées. Ce n'est donc pas ici un problème majeur. Par contre, les acides uroniques qui ne sont pas dosés peuvent représenter jusqu'à ro p. Ioo de la membrane des graminées feuillues. Nous estimons donc les membranes par défaut et parallèlement les constituants cytoplasmiques par excès. Enfin signalons à nouveau le problème de la correction de la lignine. Nous avons utilisé le même facteur de correction pour les feuilles et pour les tiges. Or, la droite de régression déjà citée a été établie pour la plante entière. Il y aurait lieu de calculer deux droites différentes pour les limbes d'une part et pour les tiges et gaines d'autre part. 
Le principal facteur des variations observées dans la fraction membranaire des plantes entières, est probablement la proportion de tiges, puisqu'au premier cycle on constate qu'à l'épiaison, les jeunes tiges sont déjà légèrement plus riches en membranes (de 3 points) que les gaines. A la floraison il y a $63 \mathrm{p}$. roo de membrane alors que les fractions tiges + gaines, dont la plus grande partie est constituée par des tiges, représentent $65 \mathrm{p}$. Ioo de la plante.

Après la fauche du premier cycle, les jeunes tiges non sectionnées se développent rapidement. Il y a pratiquement une prolongation du premier cycle avec un pourcentage de tiges beaucoup plus important (en poids). Certaines plantes (celles dont l'ébauche de l'inflorescence a été sectionnée) mettent en activité leurs bourgeons axillaires dont le développement est pondéralement peu important. Globalement, on a donc beaucoup de tiges qui pour un temps de croissance donné sont physiologiquement plus âgées. Ainsi les plantes de l'échantillon II ( ${ }^{\text {re }}$ coupe du $2^{\mathbf{e}}$ cycle) sont proportionnellement beaucoup plus riches en tiges que celles des autres échantillons qui ont eu un même temps de croissance. Il en est de même des prélèvements $\mathbf{I} 2$ et $\mathrm{I} 3$ ( $^{\mathrm{e}}$ et $3^{\mathrm{e}}$ coupes du $2^{\mathrm{e}}$ cycle) avec en plus le fait que les tiges très développées ont atteint à ce stade un état de maturité très avancé.

Nous avons noté l'évolution " anormale " des limbes du $3^{\mathrm{e}}$ cycle 33I-332-333. Au moment de la récolte, les limbes attaqués par la rouille étaient classés dans les débris. Or, les conditions en $195^{8}$ étaient particulièrement favorables à ce parasite auquel le Dactyle $S 26$ est très sensible. Ainsi, seuls les limbes jeunes étaient intacts ou peu nécrosés et donc conservés pour l'analyse. Enfin, nous avons insisté longuement, sur les conditions particulièrement favorables au développement des plantes, du printemps à l'automne. C'est peut-être une des causes de la constance relative dans les taux de membrane et dans la composition de celle-ci.

Les limbes en début de croissance contiennent plus de lignine que les tiges et les gaines. PIGDEN (I G6I) explique ceci par le fait que très tôt les limbes sont riches en tissus vasculaires, la lignine ne pénétrant les autres tissus que très tard. Par contre, les tiges et les gaines sont riches en tissus de conduction (faisceaux libéro-ligneux) et en sclérenchyme dont la lignification est profonde et progressive. Ce problème de l'évolution de la composition des membranes a été discuté en détail par JARRIGE (I963).

$$
\text { Resu pour publication en mars } 1965 .
$$

\section{SUMMARY}

5TIDIES OF VARIATIONS IN CARBOHYDRATE CONTENT OF CYTOHIASM AND MEMBRANE TISSUL OF COCKSFOOT DURING THE YEAR

The object of this study was to estimate the composition of cocksfoot (Dactylis glomerata) in the Paris Basin at different times of the year and under different systems of management.

Cocksfoot $S 26$ sown on clay-humus soil was abundantly fertilized and harvested in I958 after normal management in 1957 . The first cycle was broken at 3 different stages : leaf, ear formation and start of flowering; the later cycles after growing for four, six and eight weeks. Percentages of the different parts, leaf blade, leaf sheath, stem, flower and dead material, and their contents of reducing sugars, short-chain polysaccharides, fructosans, hemicelluloses, cellulose and lignin were estimated. 
In the first cycle the leaf blades developed most up to the start of ear formation, the time when stems and leaf sheaths grew more quickly so that they constituted about two thirds of the whole plant at flowering. In the subsequent cycles there was practically no stem. The later the season, the sooner the leaf blades reached their maximum weight, 58 days in June, 42 in September. The leaf sheaths were a fairly constant low proportion of the whole plant, i 3 to $20 \mathrm{p}$. I00 of dry matter.

There wove more reducing sugars in the first cycle, 4.2 to i $\mathrm{p}$. 100 of dry matter, than in later cycles, I.9 to 3.7 p. Ico. This difference was due mainly to the greater proportions of leaf sheath and stem in the first cycle. In all cycles stem and leaf sheath had more reducing sugars than leaf blads.

In contrast, there were larger amounts of short-chain polysaccharides in leaf blade, which contained 1.3 to 2 times as much as stem and leaf sheath. There was more in plants of the first cycle, 2.8 to 5.5 p. 100 against 1.9 to 3.2 p. I00 of dry matter of the whole plant, but high values were found also in samples harvested in autumn, 8.0 p. I 00.

In the first cycle fructosan contents were relatively high, $2.8 \mathrm{p}$. Ioo of dry matter of the whole plant. In subsequent cycles there was little, 0.003 to $0.7 \mathrm{p}$. I0o. The only exceptions were late cycles harvested in autumn. In all cases stems and leaf sheaths had more than leaf blades.

The membrane fraction was fairly constant, both quantitatively and qualitatively, average for all samples $44 \mathrm{p}$. I oo of dry matter of the whole plant. However, there were some variations, on which the greatest influences were age of the plant and proportion of stem. Thus in the first cycle membranc tissue increased from 44 to $49 \mathrm{p}$. 100 between the leaf stage and the start of flowering. The leaf blades became much more membranous as the plant aged. In some cycles there was an increase of I I points between four and eight weeks of growth. The increases of the three membranous constituents, hemicelluloses, cellulose and lignin, were parallel. There was, on average, in dry matter of leaf blades I 6 p. Ioo hemicelluloses, 22 p. Ioo cellulose and 5 p. Ioo lignin.

Stems and leaf sheaths, particularly the former, were always richer in membranous tissue than the leaf blades, sometimes with 15 to 20 points more.

At the end of growth, in the first cycle, cellulose and lignin increased while hemicelluloses remained fairly constant. On average there were in stems and leaf sheaths, excluding the first cycle, 21 p. I 00 hemicelfuloses, 25 p. I00 cellulose and 4 p. I00 lignin in dry matter.

If the composition of membranous tissue is considered as percentage of that tissue it can be seen that only in the first cycle is ther any notable variation in composition : when the plant ages hemicellulose becomes less and cellubse and lignin increase.

\section{RÉFÉRENCES BIBLIOGRAPHIQUES}

BAKER II. K., GaRwoOd li. A., Ig(1. Studies on the root development of herbages plants. V. Seasonal changes in fructosan and soluble-surar contents of cocksfoot herbages, stubble and roots under two cutting treatments. J. Brit. Grassl. Soc., 16, 263-267.

Fauconneat G., Jarrige R., 1955. Quelques problèmes physiologiques de l'utilisation de fourrages.

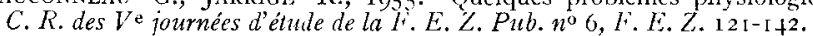

Gugélen I., Fauconneau G., ig6o. Etude sur les variations des teneurs en matières azotées et en eléments minćraux du Dactyle. Ann. Zootech., 9, I57-1 79 .

IIUokuna Ii., igoo. The effect of differential cutting on the growth of the cocksfoot. Proc. Vih Intern. Grassl. Congr ; p. 4 .

JARrige R, I954. Nature et importance des glucides solubles dans les plantes fourragères en croissance. Conférence Européenne des herbages.

JARrige R., I961. Analyse des constituants glucidiques des plantes fourragìres. I. Fractionnement des membranes par les hydrolyses acides. Ann. Biol. anim. Bioch. Biophys., 1, 163-2 1 2.

Jarrige R., I963. Les constituants nembranaires des plantes fourragères. Ann. Biol. anim. Bioch. Biophys., 3, I $43-$ r 90 .

JourNET M., JARRIGE R., 1962. Analyse des constituants glucidiques des plantes fourragères. IV. Études sur le dosage de lia ligninc. Ann. Biol, anim. Bioch. Biophys., 2, 223-250.

LaIDl.aW K. A., WYlaM C. B., I952. Analytical studies on the carbohydrates of grasses and clowers. II. The preparation of grassics samples for analysis. J. Sci. Iid. Agric., 3, 494-496.

Pilllips 'l. G., Sullivan J. T., Louginin M. E., Sprague V. G., i954. Chemical composition of some forage grasses. J. Changes with plant maturity. Agron. J., 46, 361-369.

Pigien W. J., 1953. The relation of lignin, cellulose, protein, starch and ether extract to the "curing * of range grasses. Sci. Agric., 33, 364-378.

Mc. Rary W. L., Silattery Y. (., i 945. Dosacr des fructomanes clans les végétaux. J. Biol. Chem. 157, $161-167$. 
Somogyi M., 1952. Notes on sugar determination. J. Biol. Chem., 195, 19-23.

IVAITE R., BoYD J., I953 a. The waicr soluble carbohydrates of grasses. I. Changes occurring during the normal hife cycle. f. Sci. Food. Agric., 4, 197-204.

WAITE R., BoYD J., 1953 b. The water soluble carbohydrates of grasses. II. Grasses cut at grazing height several times during the growing season. J. Sci. Food. Agric., 6, 257-261.

Warte R., 1957. The water soluble carbohydrates of grasses. III. First and second year growth. J. Sci. Food. Agric., 7, 422-428.

WAITE R., 1958. The water soluble carbohydrates of grasses. IV. The effect of different levels of fertilizer treatment. J. Sci. Food. Agric., 1, 39-43. 